\title{
Comunicação para mudança social: projeto Canal*Motoboy
}

\author{
Maria das Graças Targino* \\ Alisson Dias Gomes***
}

\section{Resumo}

$\mathrm{Na}$ atualidade, a mídia de referência enfrenta a propagação dos meios alternativos dirigidos à democratização das informações geradas por cidadãos comuns. $\mathrm{O}$ Canal*Motoboy constitui exemplo desta modalidade de comunicação. Sua proposta é consolidar uma estrutura aberta para dar voz ao coletivo de motoboys de São Paulo (SP), Brasil. Devidamente treinados e recorrendo ao celular multimídia, registram seu dia a dia no website Canal*Motoboy. Este artigo analisa o projeto, a partir da concepção da comunicação para mudança social, uma vez que o direito à liberdade de expressão, historicamente, tem sido expropriado dos cidadãos por conta da expansão vertiginosa dos conglomerados comunicacionais. Além da revisão de literatura, o objeto de estudo segue perspectiva qualitativa mediante uso das técnicas de observação e de entrevista em profundidade para obtenção de informações complementares junto aos atores do coletivo.

Palavras-chave: Comunicação para mudança social. Comunicação alternativa. Meios de comunicação alternativa. Canal*Motoboy. Democratização da informação.

* Professora colaboradora do Programa de Pós-Graduação em Comunicação (PPGCOMPI) do Departamento de Comunicação, Universidade Federal do Piauí, TeresinaPI, Brasil; Professora colaboradora do Programa de Pós-Graduação em Ciência da Informação (PPGCI) do Departamento de Ciência da Informação, Universidade Federal da Paraíba, João Pessoa-PB, Brasil. Doutora em Ciência da Informação e jornalista. Pós-Doutora em Jornalismo pelo Instituto Interuniversitario de Iberoamérica da Universidad de Salamanca, e Máster Internacional en Comunicación y Educación, na Universidad Autónoma de Barcelona, ano 2007. Autora de centenas de artigos técnico-científicos, capítulos de livros e livros nas áreas de ciência de informação e comunicação. Destaque para seu último livro Jornalismo cidadão: informa ou deforma, lançado pela Unesco. E-mail: gracatargino@hotmail.com

** Professor de Jornalismo do curso de Comunicação Social da Faculdade Santo Agostinho, Teresina-PI, Brasil. Doutor em Comunicação Audiovisual pela Universidad de Salamanca, Espanha. Mestre em Comunicação e Educação pela Universidad Autónoma de Barcelona, Espanha, ano 2007. Integra o Conselho Científico da revista Fonseca, Journal of Communication, da Universidad de Salamanca. Atuou como repórter e editor na TV Meio Norte (Rede Bandeirantes) e TV Antares (TV Cultura).E-mail: alissondg@bol.com.br 


\section{Communications for social change: project Canal*Motoboy} Abstract

Nowadays, reference media faces the alternative media propagation, which uses different means and it is based on the work of independent producers who target the information democratization in every possible format at no cost and created by "common citizens". The Canal*Motoboy, a project by the Catalan Antoni Abad, is an example of this kind of communication. He aims to consolidate an open structure in order to give voice to motoboys ${ }^{1}$ from São Paulo (SP), Brazil. After being properly trained and by using their multimedia cell phones, they register their routine on Canal*Motoboy website. This article analyzes the progress of this project, based on the communication for social change, once the right to freedom of expression, historically, has been expropriated from citizens on account of the expansion of communication conglomerates. The methodological approach will consist of observation and deep interview technique, as well as literature review.

Keywords: Communications for social change. Alternative communication. Alternative media. Canal*Motoboy. Information democratization

\section{Comunicación para el cambio social: proyecto Canal*Motoboy Resumen}

En la actualidad, los medios de comunicación de referencia se contraponen a la propagación de los medios alternativos dirigidos a la democratización de informaciones, generadas por ciudadanos comunes. El Canal*Motoboy constituye un ejemplo de esa modalidad de comunicación. Su propuesta es consolidar una estructura abierta para dar voz al colectivo de motoboys de São Paulo (SP), Brasil. Debidamente entrenados y recurriendo al teléfono móvil multimedia, registran su día-a-día en el website Canal*Motoboy. Este artículo analiza este proyecto, a partir de la concepción de la comunicación para el cambio social, una vez que el derecho a la libertad de expresión, históricamente, ha sido expropiado de los ciudadanos por cuenta de la expansión de los conglomerados comunicacionales. Además de la revisión de literatura, el objeto de estudio se ha abordado desde una perspectiva cualitativa a través de la técnica de observación y de entrevista en profundidad para las informaciones de actores del colectivo.

Palabras clave: Comunicación para el cambio social. Comunicación alternativa. Medios de comunicación alternativa. Canal*Motoboy. Democratización de la información.

\section{Introdução: novos tempos para a comunicação}

\section{comunicação humana sofre, de forma intensa, as trans-
formações radicais que, desde as décadas finais do século
passado afetam a sociedade contemporânea, por conta,}


sobretudo, da evolução das tecnologias de informação e de comunicação, com suas potencialidades quase infinitas de caráter informativo e, quiçá, educativo e formativo. Essas transmutações atingem a vida individual e profissional dos cidadãos por toda parte, na América Latina ou fora dela. Há profissões que morrem ou agonizam. Há profissões que nascem e se fortalecem. Há profissões que tendem a se modificar.

Como decorrência, percebemos profunda alteração na geografia das disciplinas científicas, mediante fusão de umas, como telemática, e ramificação de outras, como comunicação social. No Brasil, dentre suas seis habilitações - radialismo, jornalismo, editoração, cinema, publicidade e propaganda, relações públicas - o jornalismo, mais do que outras profissões, atravessa mudanças significativas. Na condição de atividade profissional de natureza social, voltada à elaboração e à divulgação de notícias em diferentes suportes, não se mantém isolado das inovações científicas e tecnológicas. Acompanha, com avidez, as tendências de cada momento histórico, mundo afora.

No entanto, nem avanços em ciência e tecnologia nem as transmutações daí advindas conseguem eliminar a correlação entre imprensa e modo de produção capitalista, na dita sociedade de informação ou sociedade do conhecimento ou sociedade da aprendizagem. Na perspectiva teórica de Williams (1989, 1992), as inovações tecnológicas constituem relevante fator de mutações sociais e culturais, com destaque para o aspecto econômico. Assim, em que pese a decantada democratização da informação via redes eletrônicas de informação e de comunicação, vivemos, hoje, um processo acelerado de mercantilização e de concentração midiática. Temos um Brasil das comunicações. A imprensa escrita, falada, televisiva e eletrônica, sob a responsabilidade direta de poderosos conglomerados comunicacionais, avança em busca de tecnologias sofisticadas e compatíveis com a realidade do século 21, perfazendo o que se chama de jornalismo de referência. Há espaços para coberturas nacionais e internacionais. Há interesse permanente para inovações em termos de produção, em qualquer instância, inclusive no espaço virtual, abrindo campo para o jornalismo digital, e, sobretudo, para o webjornalismo - jornalismo 
contemporâneo presente no espaço cibernético, dando origem ao jornalismo contemplado em portais, sites, blogs jornalísticos gerais e/ou especializados etc.

É evidente, pois, que a imprensa brasileira se desvia, mais e mais, de sua função precípua de serviço público e espaço cultural e literário. Impregnados por mercantilismo progressivo, os veículos de comunicação se deparam com pressão crescente para noticiar o "noticiável" (leia-se, vendável, em termos econômicos e políticos) em detrimento dos interesses genuínos das coletividades, gerando clima de descrédito em relação à prática ética do jornalismo.

É a confirmação do Informe McBride, que completa mais de 30 anos. À época, sua versão original intitulada Many voices, one world, elaborada durante conferência promovida pela Organização das Nações Unidas para a Educação, a Ciência e a Cultura (Unesco), em 1980, já alerta para a existência de um sistema de controle de informação ostensivamente utilizado como instrumento de dominação pelos países primeiro-mundistas. Hoje, não obstante as 82 recomendações daquele momento, Mattelart (2009) e outros estudiosos negam grandes mudanças, tal como o faz Paraná (2010), em palavras textuais que dizem:

A concentração do controle da informação consolida-se na mão de grandes conglomerados, que organizados em torno das agências de notícias monopolizam visões e versões, empobrecendo o jornalismo e a democracia.

A internet, que se imaginou revolucionar as relações comunicacionais, contribui consideravelmente para grandes transformações, mas, por si só, não é capaz de derrubar de vez os muros levantados pelas desigualdades sociais, políticas, econômicas [...]

Portanto, em diferentes contextos, é evidente o gap entre o poder de comunicação dos grupos empresariais e o que emana dos segmentos sociais. Por isso, a mídia de referência, mantida por meios de comunicação consolidados, enfrenta a propagação da comunicação para mudança social, que vem rodeada de questionamentos, sintetizados por Barranquero (2007, p.2, tradução nossa): "Que é exatamente comunicação para mudança social?; A que fazemos referência quando vinculamos estes dois termos?; Que significado assume a comunicação nos processos de desenvolvimento? Há mudança social sempre que comunicamos?" 
São questões sem respostas unívocas. Isto é, o conceito de comunicação para mudança social / comunicação alternativa (CA) é em si mesmo polêmico. Em primeiro lugar, é possível argumentar que a comunicação, em termos ideais, deve favorecer, sempre, mutações a favor da coletividade. Em segundo lugar, subsiste em outros campos. Exemplificando: em terapia ocupacional, CA define outras formas de comunicação, que englobam desde o uso de gestos e sinais, expressões faciais, emprego de pranchas de alfabeto ou de símbolos pictográficos até sistemas sofisticados, como o computador com voz sintetizada.

Diante do aparente impasse, adotamos a linha de pensamento de Morris (2004), que concebe CA como qualquer forma de expressão comunicativa que prioriza o bem-estar social e a qualidade de vida da população. Lembrando que os termos - convencional, tradicional e similares - são aqui utilizados em oposição à mídia alternativa, esse autor arrola quatro categorias de imprensa alternativa: (1) meios de comunicação alternativos; (2) movimentos sociais; (3) meios de comunicação locais ou regionais; (4) meios de comunicação alternativos com participação direta dos cidadãos. De forma sucinta, o primeiro grupo diz respeito à emergência, manutenção e expansão de variados meios de comunicação não tradicionais. Em esfera nacional, lembramos a Agência Capão de Repórteres Populares. Há, ainda, na internet, em profusão, sites de movimentos sociais, alguns de repercussão mundial, como o GreenPeace ou de impacto nacional, como o Movimento dos Trabalhadores Sem Terra. No terceiro grupo, os meios de comunicação locais ou regionais alternativos, desde o século 19, já apresentam amplas perspectivas políticas graças a estações de rádio e jornais ou boletins comunitários independentes. Rádios comunitárias, jornais de bairro se fazem notar por todas as regiões brasileiras, à semelhança da atual Rádio Muda FM (Campinas, São Paulo, SP). Como quarta modalidade, os meios de comunicação alternativos com participação direta dos cidadãos.

Esta quarta categoria de CA tem nos centros de mídia independentes seus mais legítimos representantes. O Independent Media Center (IMC), por meio do site Indymedia e dos coletivos de 57 países espalhados nos cinco continentes, incluindo represen- 
tação em território brasileiro (o Centro de Mídia Independente, CMI Brasil), é o modelo mais genuíno desse novo tipo de fazer jornalístico. Os IMC e CMI, ao lado de outras iniciativas, como overmundo, rebelion, slashdot e kuro5hin, na conjuntura de webjornalismo social (em oposição ao webjornalismo de referência, mantido por meios de comunicação consolidados), favorecem a grupos minoritários e a qualquer indivíduo em particular o direito de se fazer ouvir, delineando-se como projeto midiático e democrático dedicado à justiça social e econômica (Targino, 2009).

Ainda que nem todos os conteúdos possam ser categorizados como jornalísticos, o fato é que uma gama de autores (BARBOSA, 2007; BARDOEL; DEUZE, 2001; BRAMBILLA, 2006; HYDE, 2002; PRYOR, 2002) denomina este novo fazer de open source journalism ou jornalismo de fonte aberta ou participativo ou cidadão ou cívico ou jornalismo ou jornalismo digital de terceira geração ou 3.0 ou web colaborativo ou web social ou internet de nova geração ou software social. Mais uma vez, enfrentamos terminologias em construção, as quais, em sua essência, possuem concepção idêntica. Este novo tipo de jornalismo visa impulsionar a democratização de informações, em diferentes suportes, em qualquer formato e a custo zero, geradas por indivíduos comuns, independentemente de suas características individuais e sociais. É a difusão de ideias no contexto da filosofia de publicação aberta, que nada mais é do que a veiculação de informações no espaço virtual, de imediato, por meio de um computador conectado à internet.

É nessa conjuntura que chama a atenção a iniciativa do Canal*Motoboy, projeto do artista catalão Antoni Abad, cuja proposta é consolidar uma estrutura aberta para dar voz ao coletivo de motoboys de São Paulo capital, Brasil. Devidamente treinados, são incentivados a produzirem notícias midiáticas sobre seu cotidiano. Recorrendo ao telefone celular multimídia, registram seu dia a dia ou qualquer tema de interesse no site Canal*Motoboy (http://www.megafone.net/ SAOPAULO/intro.php?qt=0), utilizando fotos, vídeos e áudios, enviados ao portal pelo Multimedia Messaging Service (MMS). Ressaltamos que se trata de experiência bem sucedida, com ampla repercussão nacional, apesar de pouco estudada no circuito acadêmico e científico, destacando-se o trabalho de Brunet (2009). 
Sob esta perspectiva, este artigo visa analisar o andamento deste projeto, a partir da concepção da comunicação para mudança social sustentada por autores, como Barranquero (2007); Mattelart (2009); Morris (2004), aqui sintetizada por Castells (2010, p. 393, tradução nossa):

A mudança social é multidimensional, mas, em última instância, é o contingente à mudança de mentalidade, tanto para os indivíduos como para os coletivos. A forma em que pensamos e sentimos determina a forma como atuamos. $\mathrm{E}$ as mudanças na conduta individual e na ação coletiva, sem dúvida, influem e modificam, de forma gradual, as normas e as instituições que estruturam as práticas sociais.

\section{Sobre o Canal*Motoboy}

Eis palavras literais de abertura do site Canal*Motoboy (Figura 1), mantido, nos dias atuais, com o apoio de órgãos governamentais e privados, a exemplo do Centro Cultural São Paulo, Prefeitura da Cidade de São Paulo, Fundação Armando Álvares Penteado (FAAP), Embaixada da Espanha no Brasil, Sociedad Estatal para la Acción Cultural Exterior e Cooperación Cultural Exterior Española:

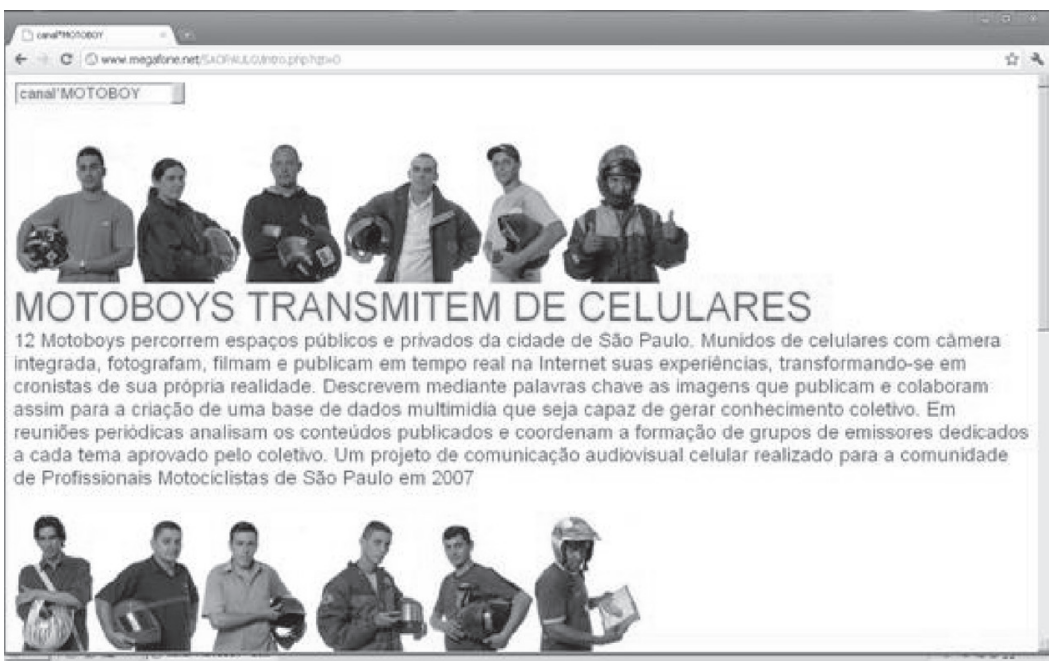

Figura 1 - Página central del website Canal*Motoboy 
Motoboys percorrem espaços públicos e privados da cidade de São Paulo. Munidos de celulares com câmera integrada, fotografam, filmam e publicam em tempo real na internet suas experiências, transformando-se em cronistas de sua própria realidade. Descrevem mediante palavras-chave as imagens que publicam e colaboram assim para a criação de uma base de dados multimídia que seja capaz de gerar conhecimento coletivo. Em reuniões periódicas analisam os conteúdos publicados e coordenam a formação de grupos de emissores dedicados a cada tema aprovado pelo coletivo. Um projeto de comunicação audiovisual celular realizado para a comunidade de profissionais motociclistas de São Paulo em 2007 (Canal*Motoboy, 2011, grifo nosso).

Neste trecho, os motoboys sintetizam sua intenção: divulgar, em tempo real, via internet, seu dia a dia e transformar-se em "cronistas de sua realidade", favorecendo "conhecimento coletivo" inter e intra comunidade, mas, sobretudo, extra comunidade. Isto é, ao tempo em que o Canal... privilegia um coletivo específico (profissionais motociclistas de SP), permite que a sociedade paulistana e brasileira conheça a realidade desses trabalhadores. Isto significa a concretização de ações efetivas de novos atores sociais para a democratização da informação, nos moldes da CA, com a observação relevante de que, em geral, os motoboys são retratados de forma negativa na imprensa de referência. A explicação é que, nas cidades de porte médio ou nas metrópoles, há incidência elevada de assaltos e de outros delitos cometidos por motociclistas, o que imprime ao projeto maior relevância social.

Apesar da dificuldade de se conseguir dados estatísticos confiáveis sobre crimes de roubos, latrocínios e homicídios, em que motos são utilizadas na fuga e no acesso aos centros urbanos, sistematicamente, o Comando de Policiamento de Trânsito realiza operações policiais, a exemplo da "Operação Cavalo de Aço", com o intuito de inspecionar as motocicletas que circulam na cidade de SP. Há, ademais, estudos sobre a ocorrência de delitos envolvendo motoboys brasileiros, à semelhança do intitulado Crimes praticados por marginais conduzindo motocicletas, da autoria de Valter Souza Menezes, Comandante de Rondas Especiais da Polícia Militar da Bahia, Brasil.

Tudo isto acentua o temor da população frente aos motoboys. E mais, agrava o desconhecimento do risco a que estão subme- 
tidos e de sua luta diária como brasileiros, que sobrevivem com renda mensal em torno de $\mathrm{R} \$ 1.090$ (dois salários mínimos) por uma jornada diária de oito horas. Além do mais, segundo dados do Sindicato dos Mensageiros Motociclistas (Sindimotosp) e da Associação dos Motociclistas e Mensageiros do Estado de São Paulo (AMM), significativa parcela trabalha como esporádico e recebe, então, uma média de $\mathrm{R} \$ 6$ por hora.

Como classe profissional relativamente nova, sua realidade é retratada por Eliezer Muniz, curador adjunto do projeto e um dos coordenadores, aqui sintetizada:

A profissão de motociclista - atividade remunerada que faz uso da motocicleta para execução de diversas tarefas, como entregas e retiradas de documentos, cheques, malotes, medicamentos, alimentos e todo tipo de pequenos volumes e componentes, que prescindem de certa urgência -, surge no Brasil a partir do início dos anos 80. Cresce, exponencialmente, após a Constituição de 1988, com a terceirização e o fortalecimento do setor de serviços.

As primeiras empresas de entregas rápidas [...] que começam a substituir seus office boys, pelos mensageiros motorizados, datam de 1983/84, e em menos de uma década já existiam mais de 30 mil mensageiros apenas na Capital de São Paulo.

Este rápido crescimento se deve a vários fatores. Mas o principal foi [...] relação custo / benefício - que reduzia os gastos trabalhistas, e otimizava os serviços das empresas contratantes (clientes) que passariam cada vez mais a utilizar este novo modo de produção [...] (THE ABAPORU PROJECT ON TECHNOLOGY APPROPRIATION, 2007).

Ao incremento de serviços de entrega em domicílio, unem-se outros fatores que explicam a expansão de motoboys em SP (366,6\% nos últimos 10 anos, saltando de 30 mil para 140 mil): rapidez e mobilidade da moto para circular nas vias congestionadas; baixo custo para compra do veículo; facilidade em conseguir trabalho informal; e falta de regras alusivas à circulação nas ruas. No entanto, são muitos os problemas que cercam a profissão. Além do repúdio de parte da sociedade, os motoboys enfrentam riscos contínuos de acidentes de trânsito. Segundo The Abaporu Project on Technology Appropriation (2007) e o jornalista Adhemar Altieri (2004), diariamente, em média, morre um motociclista no trânsito da capital SP. Há, ainda: falta de garantias trabalhistas, inadequada 
regulamentação jurídica, fragilidade dos órgãos representativos da categoria (Sindimotosp e AMM), com o agravante de que, segundo o jornal Folha de S.Paulo, dos 140 mil motoboys, apenas $18 \mathrm{mil}$ possuem registro junto à Delegacia Regional do Trabalho.

São constatações que acentuam a responsabilidade da proposta de comunicação para mudança social do Canal*Motoboy, até porque, apesar de mais de três anos de funcionamento e de o site fazer alusão a 12 motoboys (11 homens e uma mulher), o acréscimo ao grupo inicial é muito pequeno: hoje, são 18 participantes, entre os quais, há, agora, duas mulheres.

\section{Procedimentos metodológicos}

Para a consecução desta pesquisa descritiva de caráter qualitativo, além de revisão de literatura sobre o tema, recorremos à técnica de observação direta, com verificação in loco, de forma sistemática e planejada, da dinâmica do Canal*Motoboy, de novembro de 2010 a fevereiro de 2011. A fim de complementar os dados e dirimir dúvidas, contatamos os 18 participantes mediante formulário de coleta de dados por e-mail, entre 1 a 28 de fevereiro de 2011. Diante da mensagem de um dos líderes, datada em 13 de março, de que, "infelizmente não foi possível termos todos os questionários respondidos pelos motoboys, uma vez que o contato com eles é muito difícil e [...] para realizarmos uma reunião aqui é preciso muita antecedência”, decidimos recorrer à técnica de entrevista em profundidade. Esta consiste em "[...] recurso metodológico que busca, com base em teorias e pressupostos definidos pelo investigador, recolher respostas a partir da experiência subjetiva de uma fonte, selecionada por deter informações que se deseja conhecer" (DUARTE, 2008, p.62).

No caso, priorizamos os dois coordenadores, Eliezer Muniz e Ronaldo Simão da Costa, e, ainda, o participante com maior número de postagens em 2011. Além de sua função de coordenador, Muniz é autor do livro Coletivo Canal*Motoboy: o nascimento de uma categoria, editado, em 2010, por Aeroplano Editora, Rio de Janeiro. E os três entrevistados, além de disposição para quaisquer informações, são pioneiros do Canal..., e, portanto, com condições de suprir informações extras, não captadas pela observação. 
O formulário de coleta compreende perguntas abertas, mistas e fechadas. A primeira seção (A) traz cinco questões referentes à identidade do respondente: nome (controle interno); sexo; faixa etária; estado civil; e escolaridade. A seguir, mais quatro perguntas fechadas sobre a atuação junto ao Canal*Motoboy: tempo de adesão; frequência com que colabora; autoavaliação como colaborador; benefícios que a proposta traz à sua vida.

A segunda parte (B) do roteiro de entrevista destina-se a entender o funcionamento do Canal*Motoboy, por meio de nove questionamentos, alguns dos quais com desdobramentos: existência de liderança / coordenação; processo de seleção do material - quem seleciona, existência de critérios ou liberdade irrestrita. Perguntamos, ainda, sobre a existência de treinamento inicial e de reciclagens sistemáticas. Em ambos os casos, se positivo, pedimos para identificar organizadores, ministrantes e conteúdos. Prosseguindo, as últimas três questões, inteiramente livres, estimulam os motoboys a refletirem sobre sua atuação como comunicadores e, por conseguinte, como formadores de opinião: (1) o que você acha que deveria mudar no funcionamento do Canal*Motoboy?; (2) que transformações trouxe à sua vida?; (3) conte-nos um relato que lhe emocionou e que está em "seu" website.

\section{Motoboys e comunicação para mudança social}

Como visto, talvez face às condições de trabalho, há primazia do sexo masculino, mas não há prevalência dos muito jovens, e, sim da faixa etária de 30 a 40 anos e do estado civil casado. Quanto à escolaridade, todos têm, no mínimo, o ensino fundamental, com três $(16,67 \%)$ deles com formação superior, um dos quais, no momento, cursando pós-graduação lato sensu.

Considerando que a equipe inicial de 12 cidadãos se mantém desde sua criação, em 2007, com apenas seis novos membros, o tempo de atuação com maior representatividade se refere à alternativa - mais de três anos, com $66,67 \%$ contra $33,33 \%$ dos que estão no projeto de um a três anos. No entanto, contrariando as expectativas em termos de compromisso social quanto ao fato de que há um longo caminho a percorrer rumo à conquista dos 
direitos humanos, em particular, na comunicação, a inconstância dos colaboradores preocupa. Decerto, "novas formas de cidadania precisam ser imaginadas e conquistadas em função das necessidades dos nossos tempos, com o objetivo de materializar uma participação ativa dos cidadãos na vida social" (MATTELART, 2009, p.35, grifo nosso). Porém, a observação das postagens de cada um deles revela irregularidade e desatualização.

Para que se tenha ideia, em 2011, até o dia 12 de março, são somente 158 posts, e, mais grave, distribuídos entre três únicos $(16,67 \%)$ motociclistas. O número destoa com o total de 13.443 postagens de 2007 até a referida data e contradiz a essência do projeto no sentido de o Canal... ter como proposta central documentar o cotidiano do coletivo. Há, pois, distanciamento entre teoria e prática. Afinal, os entrevistados reconhecem que sua atuação junto ao website nada tem de lazer. Ao contrário, segundo os posicionamentos por eles expressos, representa prática midiática, exercício de cidadania, ação política e ação social, com flagrantes benefícios para sua vida. A experiência lhes propicia chance de escrever / publicar, intercambiar informações, aprofundar temas, nutrir intenso sentimento de liberdade, fortalecer-se como profissional e, ainda, conhecer com mais profundidade a realidade do Brasil, em particular de SP capital. Quer dizer, os motoboys, em termos teóricos, concordam com as palavras de Castells (2010, p.23, tradução nossa):

Sem dúvida, a mudança social e política tem ocorrido por todas as partes e em todas as épocas a partir de milhares de ações gratuitas e em ocasiões tão inutilmente heróicas [...] que não guardam proporção direta com sua eficácia. Gotas de chuva incessante de luta e de sacrifícios que terminam inundando os baluartes da opressão se os muros de incomunicação entre solidões paralelas começam a ruir e os espectadores se convertem em atores $[\ldots]$

Em termos de estrutura, em consonância com a proposta de comunicação para mudança social, o Canal*Motoboy mantém design acessível com espaços individuais e espaços coletivos. No entanto, paradoxalmente, carece de esclarecimentos sobre seu funcionamento, de modo que conhecer sua dinâmica requer tempo. 
Isto contraria os princípios elementares dos serviços de informação em rede, que pretendem responder às demandas informacionais, em tempo recorde e de forma amigável. As postagens estão distribuídas sob tags ou palavras-chave. Estas, porém, são bastante disformes, no sentido de que nem seguem estrutura lógica nem padronização, terminando por pulverizar os conteúdos. Isto é, cada um adota rubricas a bel prazer. Há itens muito genéricos: acidente, arte na rua, família, lazer, moradores de rua, motos, São Paulo, sindicato, trabalho, trânsito. Há itens muito pessoais: amigos, eu, festa, minha vida, prêmio, samba e sonho.

Há uma coordenação à frente do projeto e, também, treinamento para os componentes do grupo, no momento de sua adesão ao projeto. A princípio sob a responsabilidade de Antoni Abad e, posteriormente, dos coordenadores, os conteúdos das reciclagens privilegiam a configuração dos celulares; construção, configuração e operacionalização da própria página eletrônica (como enviar, editar, enviar pautas combinadas etc.); técnicas fotográficas e de produção de vídeos; organização e cobertura de eventos; modelo de organização das reuniões periódicas com o coletivo.

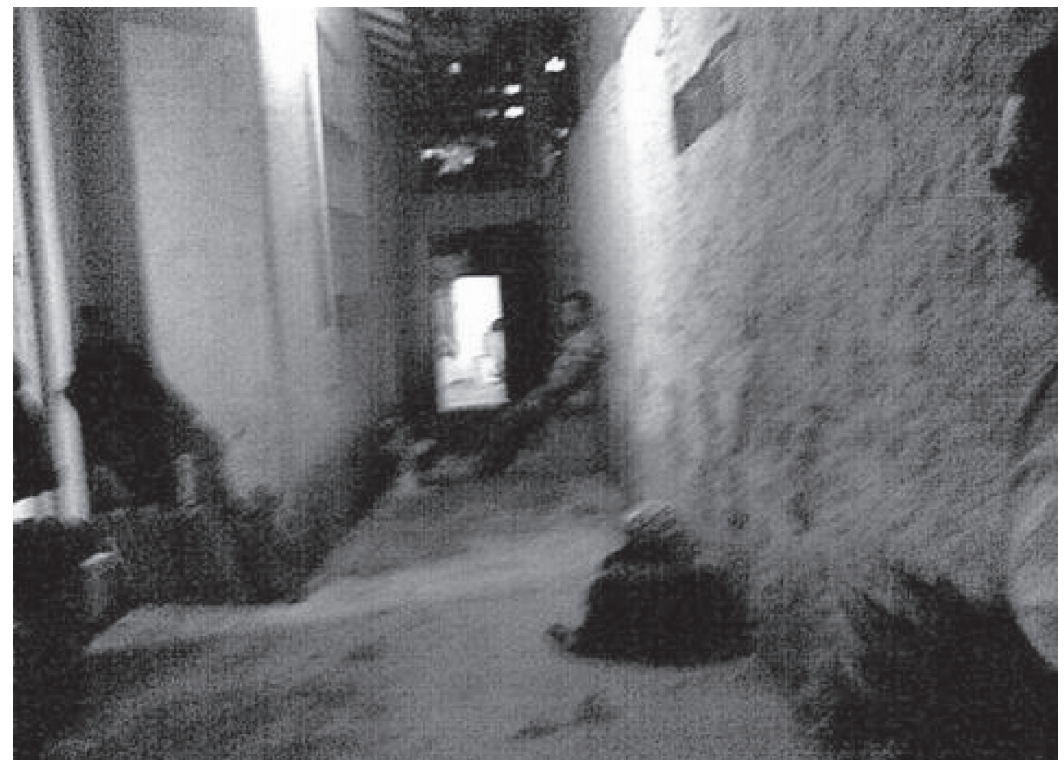

Figura 2 - Exemplo de incomunicação, website Canal*Motoboy 
Porém, no dia a dia, dentro de cada etiqueta, o motoboy assume responsabilidade integral por suas postagens. Inexiste qualquer critério de seleção e de edição: as respostas dos entrevistados comprovam que compete a cada um eleger seus posts, o que termina por comprometer a qualidade da comunicação. Ora, são fotos chocantes, sobretudo, de acidentes; ora, são fotos que nada comunicam.

O risco, então, é a adesão ao "modelo de superfície" ou "modelo de superfícies múltiplas", em que o mundo "[...] perde sua profundidade e ameaça em se converter numa superfície brilhante, numa ilusão estereoscópica, num fluxo de imagens fílmicas carentes de densidade." (MATTELART; MATTELART, 1997, p.119, tradução nossa). Definitivamente, a falta de profundidade pode atingir a sociedade contemporânea, e alcançar a comunicação para mudança social ou o jornalismo cidadão, conduzindo à fragmentação e ao excesso de informações. Além de alimentar o "mal do século", qual seja, a ansiedade de informação e o desejo desenfreado de se manter ou se mostrar atualizado perante os olhos do outro (competição e competitividade crescentes em nosso século), o indivíduo precisa desenvolver mecanismos de busca mais e mais apurados.

Então, retomando o website per se, expomos sua estrutura em ordem sequencial como está na internet, com o adendo de que obedecemos fielmente à apresentação gráfica de cada grande item (uso de palavras maiúsculas, sinais de pontuação etc.):

1. CANAL*MOTOBOY - identificação dos participantes com breve nota sobre finalidade do site, patrocinadores e colaboradores, Figura 1.

2. canal*AMBIENTAL - denúncia, recorrendo sobretudo a fotos, acerca da degradação ambiental das grandes cidades, em especial, SP. São 16 palavras-chave variadas. Exemplificando: buraco, chuva, cidade limpa, desperdício, entulhos, incêndio, lixo, poluição e vazamento. Há vivências, consideradas pelos entrevistados, como valiosas, à semelhança de visita que os motoboys fizeram aos mananciais da capital SP em parceria com o Instituto Socioambiental. 
3. canal*DIAaDIA - registro do cotidiano dos motociclistas, também sob tags, desta vez, mais numerosas, 78. Exemplificando: discriminação; estacionamento; exposição; festival; gasolina; leis e motogirl.

4. canal*PALAVRAS - dicionário volumoso com a infinidade de palavras-chave em ordem alfabética usadas ao longo do website. Um clique em qualquer uma delas remete às postagens.

5. EMISSORES - canal que remete às postagens de cada um dos participantes, graças a um simples clique no nome. Na página inicial, a identificação se dá, prioritariamente, mediante o nome verdadeiro. No decorrer das postagens, é comum a adoção de cognomes, a exemplo de Vira-lata, Beiço, Mirtão, Neka, Pirituba e Remoto.

6. MEIOS - link que documenta notícias de interesse da categoria profissional veiculadas pela mídia de referência, em qualquer suporte. Segundo The Abaporu Project on Technology Appropriation (2007), há crescente aceitação do Canal*Motoboy por parte da mídia de referência, ênfase para a Folha de S.Paulo.

7. FÓRUM - espaço destinado à troca de informações e de opiniões entre eles. Trata-se do único momento em que os motoboys se expressam por textos, ainda que curtos. Sua produção se limita ao envio de imagens fixas (fotos) ou de imagens móveis (vídeos) e alguns áudios, acrescentando-se que as fotos, em sua maioria, aparecem sem legenda.

8. ? - textos e programação paralela, ou seja, espaço infinitamente democrático, em que temas, aspectos ou formas de abordagem de sua produção não são predeterminados, o que representa "faca de dois gumes", haja vista a relevância da seleção e da editoração de conteúdos em qualquer circunstância, incluindo a CA e o jornalismo cidadão.

9. Motoboy*CULTURAL - matérias de cunho cultural, como divulgação sobre a I Semana de Cultura Motoboy. Veicula vídeos com depoimentos dos participantes na grande mídia, tal como entrevista na TV Cultura; no Portal IG - New TV; em Mídias Nativas (Universidade 
de São Paulo). Traz também informações sobre o citado livro de Muniz.

10. megafone.net - convite para grupos de pessoas em risco de exclusão social a fim de que expressem opiniões e divulguem vivências em reuniões presenciais ou via celulares. Ao permitir que os motociclistas registrem sons e imagens, publicando-os imediatamente na web, os "[...] telefones móveis se convertem em megafones digitais, que amplificam a voz de pessoas e minorias ignoradas ou desfiguradas pelos meios de comunicação predominantes" (Canal*Motoboy, 2011).

Verdade que o Canal... não se enquadra na modalidade de jornalismo participativo, até porque esta não é sua proposta, tanto pelo tipo de material postado como pelos próprios conteúdos, que se distanciam dos critérios de noticiabilidade, que comportam os valores notícia (news value), elementos que determinam se um tema é passível ou "merecedor" de se transformar em notícia. Tais critérios, descritos por diferentes teóricos, como Pamela Shoemaker, Michael Schudson, Mauro Wolf e Nelson Traquina, e sintetizados em tese de pós-doutoramento de Targino (2009) advêm não só das singularidades do campo e da cultura profissional, e dos valores daí decorrentes, como também da organização do trabalho. Afinal, se, de forma ingênua, assumirmos que tudo o que circula na internet, em blogs ou em sites participativos, é jornalismo, estamos endossando a "morte" do jornalismo, no sentido literal do termo.

Mas, é evidente que o Canal*Motoboy se organiza em torno de questões significativas para a classe, expondo suas contradições e sempre à busca de maior diálogo com a sociedade para solução de seus problemas diários, anteriormente citados, com destaque para a violência do trânsito, precariedade da regulamentação trabalhista e falta de reconhecimento da classe. Por exemplo, o risco frequente a que estão submetidos justifica a alta incidência de postagens sob tags - acidente e trânsito - que mostram como desafiam o perigo, tal como um videoclipe postado por Vira-lata (http://abaporu.net), em que mostra como "driblar" os motoristas de outros veículos em plena hora de rush na Avenida Paulista. Afi- 
nal, é evidente que essas corridas para o profissional motociclista não é mero jogo, mas, sim, parte integral de seu trabalho, uma vez que quanto mais rapidamente cruze a cidade, maior chance tem de ganhar um pouco mais. Vemos, assim, a CA como denúncia do modus vivendi de uma classe de profissionais ou porta-voz de uma categoria profissional.

Para The Abaporu Project on Technology Appropriation (2007), o Canal*Motoboy estabelece nova sociabilidade com a coletividade por meio de forma inédita de auto-representação. $O$ grupo participante conserva a autonomia imprescindível para construção social (ainda que lentamente) do direito à comunicação como parte integrante dos direitos humanos, na perspectiva de comunicação para mudança social, apregoada por Barranquero (2007); Castells (2010) e Mattelart (2009), entre outros. Experiências, como esta, guardam como traço distintivo a participação direta dos cidadãos na produção, na difusão e na troca de matérias via portais, grupos de discussão, chats, e-mails etc., sob a égide da confiança ilimitada que os meios alternativos nutrem por seus usuários-autores. Há, agora, visível "realinhamento" dos indivíduos que se alternam em posições e papéis: ora, leitor; ora autor; ora, editor; ora, crítico e assim por diante.

A meta central é permitir a cada indivíduo não somente consumir, mas, sobretudo, produzir informações verdadeiras, autênticas e acessíveis aos demais, de forma crítica e racional. $\mathrm{O}$ fundamento de uma comunicação democrática está na liberação da potencialidade dos indivíduos e dos grupos sociais em determinada cultura, com vistas a possibilitar respostas de questões complexas e controversas, como a formulada por Barranquero (2007, p.2): "Como enfrentar [...] as necessidades de comunicação dos setores mais desprotegidos da sociedade - infância, anciãos, grupos étnicos minoritários, indigentes, descapacitados etc.? [...]" Acrescentamos: os motoboys paulistanos, desprotegidos em termos de segurança e de regulamentação trabalhista e submetidos à depreciação de parte da sociedade.

\section{Considerações finais}

Por fim, impossível negar o valor de iniciativas que reforçam a comunicação para mudança social, à semelhança do 
Canal*Motoboy. Este revela a luta dos motoboys paulistanos, que estão a serviço das coletividades, na cidade maior e mais rica do Brasil, com cerca de 18 milhões de habitantes, mas cujas diferenças sociais de tão graves levam Altieri (2004, tradução nossa) a perguntar literalmente: "A democracia está funcionando?"

Por outro lado, se a falta de textos está prevista na proposta do Canal..., cujo instrumento-mor é o telefone celular multimídia, não podemos negar que há problemas na estruturação do website. Entre eles: (a) falta de informações sobre sua dinâmica; (b) desatualização das postagens; (c) falta de seleção e de edição dos conteúdos: tags muito particulares fragmentam as matérias, há excessiva valorização da vida privada dos sujeitos em detrimento de sua função social. Exemplificando: quando solicitado para relatar algo emocionante em sua vivência junto ao projeto, enquanto alguém lembra a entrega do Prêmio Orilaxé concedido pelo Grupo Cultural Afro Reggae ao Canal*Motoboy como veículo de comunicação, um outro respondente menciona a premiação de uma de suas fotos numa exposição, em patente valorização do particular sobre o social. É um dado isolado mas que retoma o pensamento de Williams $(1989,1992)$, para quem a tecnologia determina transformações na sociedade, mas a informação se sobressai como recurso econômico fundamental, interferindo não apenas em valores coletivos, mas também pessoais.

No entanto, em termos gerais, prevalece a intenção de fortalecer a comunicação para transformações mediante aproximação com a sociedade e valorização da categoria. Isto permite inferir que o Canal*Motoboy consiste em autêntico exemplo de CA, como comprova a adesão de órgãos que lhe apóiam, incluindo uma instituição de ensino superior (FAAP), embaixada e órgãos governamentais ou como referendado pelos entrevistados ${ }^{1}$ :

[...] Através dessa experiência midiática, na confluência das redes e imediata publicação na web dos conteúdos via mídias móveis, pudemos observar que [...] os emissores tiveram acesso a uma cidadania antes impensável. Na convergência da mobilidade, da motocicleta e dos celulares, estas tecnologias possibilitaram uma nova forma das cidades terem acesso a um conjunto de informações antes pouco observadas [...], colocando os

${ }^{1}$ Entrevista concedida aos autores em fevereiro de 2011. 
motoboys como sujeitos dessa relação, ao mesmo tempo em que eles buscam seu reconhecimento.

[O Canal*Motoboy] me incluiu na era digital [...] Tive que praticar o uso de computadores e internet, ampliando [...] meus horizontes e despertando a curiosidade sobre tudo que tem ligação com computadores.

Por tudo isto, em oposição aos registros desfavoráveis de Menezes (2011), devemos valorizar os pontos positivos da experiência, que vem mostrando a face mais verdadeira da categoria de motoboys. Isto se dá graças aos posts que mostram riscos a que os motoboys estão sujeitos a cada instante (tags acidente e trânsito); fragilidade da regulamentação profissional (tags sindicato e trabalho); preocupação em abrir perspectivas de uma vida cultural para a classe (motoboy*CULTURAL); conscientização crescente com o meio ambiente (canal*AMBIENTAL); e, principalmente, possibilidade de dar voz a quem nem sempre tem acesso à imprensa de referência (canal*DIAaDIA, EMISSORES, FÓRUM, megafone.net). Lembramos que além da repercussão do livro publicado sobre a experiência (Muniz, 2010), segundo The Abaporu Project on Technology Appropriation (2007), o projeto vem sendo implantado em outras cidades do mundo, com comunidades em dificuldades parecidas com as dos motoboys de São Paulo. Além do mais, assegurando a visibilidade da luta cotidiana da classe o Canal*Motoboy está em diferentes redes sociais, tais como orkut, twitter, blogger e facebook.

Em outras palavras, trata-se de luta contínua e cujos efeitos virão a médio ou longo prazo, reforçando Castells (2010, p.394, tradução nossa), quando diz:

[...] nenhum processo de mudança social é geral e instantâneo. Muitas mudanças ocorrem em ritmos diferentes em diferentes grupos, territórios e âmbitos sociais. $O$ conjunto de tais mudanças, com suas contradições, convergências e divergências constitui o tecido da transformação. As mudanças não são automáticas. Resultam da vontade dos atores sociais, guiados por suas capacidades cognitivas e emocionais em suas interações recíprocas e com o entorno. Nem todos os indivíduos se inserem no processo de mudança social, porém, ao largo da história sempre há indivíduos que o fazem e, assim, se convertem em atores sociais. Os outros são "folgados", como diria a teoria. Ou, segundo minha própria terminologia, parasitas egoístas do curso da história. 


\section{Referências}

THE ABAPORU PROJECT ON TECHNOLOGY APPROPRIATION. [Informações gerais]. 2007. Disponível em: <http://abaporu.net>. Acesso em: 18 fev. 2011.

ALTIERI, A. Letter: Sao Paulo's balancing act. 2004. Disponível em: < http:// news.bbc.co.uk/2/hi/ programmes/3570402.stm >. Acesso em: 5 jan. 2011.

BARDOEL, J.; DEUZE, M. Network journalism: converging competences of media professionals and professionalism. Australian Journalism Review, v. 23, n. 2, p. 91-103, 2001. Canberra.

BARBOSA, Suzana (Org.). Jornalismo digital de terceira geração. Covilhã, Portugal: Universidade da Beira Interior, 2007.

BARRANQUERO, A. Concepto, instrumentos y desafíos de la edu-comunicación para el cambio social. Comunicar, v. 15, n. 29, p. 115-120, 2007. Huelva.

BRAMBILLA, Ana Maria. Jornalismo open source: discussão e experimentação do OhmyNews International. 2006. 248 f. Dissertação (Mestrado em Comunicação e Informação) - Faculdade de Biblioteconomia e Comunicação da Universidade Federal do Rio Grande do Sul, Porto Alegre. 2006.

BRUNET, K. Telefone celular como instrumento de inclusão digital: estudo de caso do projeto Canal*Motoboy. In: TARGINO, M. das G. et al. Comunicação, educação e cultura na era digital: INTERCOM Nordeste 2009. Teresina: Edufpi, 2009.

CANAL*MOTOBOY, São Paulo (Brasil). [Informações gerais]. Disponível em: < http://www. megafone.net/SAOPAULO/intro. php?qt=0>. Acesso em: 01 mar. 2011.

CASTELLS, M. Comunicación y poder. Alianza: Madrid, 2010.

DUARTE, Jorge. Entrevista em profundidade. In: DUARTE, J.; BARROS, A. (Org.). Métodos e técnicas da pesquisa em comunicação. 2. ed. São Paulo: Atlas, 2008. p. 62-82.

HYDE, G. Independent Media Centers: cyber-subversion and the alternative press. First Monday, v. 7, n. 4, Apr. 2002. Illinois.

MATTELART, A. A construção social do direito à Comunicação como parte 
integrante dos direitos humanos. Intercom: Revista Brasileira de Ciências da Comunicação, v. 32, n.1, p. 33-50, jan. / jun. 2009. São Paulo.

MATTELART, A; MATTELART, M. Historia de las teorías de la comunicación. Barcelona: Paidós, 1997.

MENEZES, V. S. Crimes praticados por marginais conduzindo motocicletas. 2011. Disponível em: < http://www.agepol.org.br/cenajuronline/arquivos_noticias/Crimes_praticados_por_marginais_conduzindo_motocicletas_valter_menezes.pdf>. Acesso em: 14 fev. 2011.

MORRIS, D. Globalization and media democracy: the case of Indymedia. In: SCHULER, D.; DAY, P. (Ed.). Shaping the network society: the new role of civil society in cyberspace. 2. ed. Cambridge, Massachusetts: The MIT Press, 2004.

MUNIZ, E. Coletivo Canal*Motoboy: o nascimento de uma categoria. Rio de Janeiro: Aeroplano, 2010.

PARANÁ, E. Informe McBride, 30 anos depois: o retrato de uma comunicação mundial concentrada. 2010. Disponível em: <http:// brasiledesenvolvimento.wordpress.com /2010/ 07/ 20/ informe-mcbride-30anos-depois-o-retrato-de-uma-comunicacao-mundial-concentrada $>$. Acesso em: 8 mar. 2011.

PRYOR, L. The third wave on online journalism. The Online Journalism Review, 18 Apr. 2002. Disponível em: < http://www.ojr.org/ojr/ future/1019174689.php >. Acesso em: 14 mar. 2011.

TARGINO, M. das G. Jornalismo cidadão: informa ou deforma? Brasília: Unesco / Ibict, 2009.

WILLIAMS, R. Culture and society. London: Penguin, 1992. . The politics of modernism: against the new conformists. 2. ed. London: Verso, 1989. p.119-139.

Recebido em: 28.01.2011 Aceito em: 30.06.2011 
